Canadian Journal of Physics

Canadian

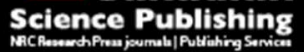

Revue canadienne de physique

\title{
Analysis of the Xylenol Isomers by Femtosecond Laser Time of Flight Mass Spectrometry
}

\begin{tabular}{|r|l|}
\hline Journal: & Canadian Journal of Physics \\
\hline Manuscript ID & cjp-2017-0762.R1 \\
\hline Manuscript Type: & Article \\
\hline Date Submitted by the Author: & 27-Dec-2017 \\
\hline Complete List of Authors: & $\begin{array}{l}\text { Kepceoğlu, A.; Selcuk Universitesi, Physics } \\
\text { Köklü, N.; Selcuk Universitesi, Technical Sciences Vocational High School } \\
\text { Gündoğdu, Y.; Selcuk Universitesi, Physics } \\
\text { Dereli, Ö.; Necmettin Erbakan Universitesi, Physics } \\
\text { Kilic, H.S.; Selcuk Universitesi, Physics }\end{array}$ \\
\hline Keyword: & $\begin{array}{l}\text { lasers, multiphoton ionisation, time of flight mass spectrometry, Density } \\
\text { Functional Theory, femtochemistry }\end{array}$ \\
\hline $\begin{array}{r}\text { Is the invited manuscript for } \\
\text { consideration in a Special } \\
\text { Issue? : }\end{array}$ & \begin{tabular}{l} 
33rd International Physics Conference of Turkish Physical Society \\
\hline
\end{tabular} \\
\hline
\end{tabular}




\title{
Analysis of the Xylenol Isomers by Femtosecond Laser Time of Flight Mass Spectrometry
}

\author{
A. Kepceoğlu ${ }^{1}$, N. Köklü ${ }^{2}$, Y. Gündoğdu ${ }^{1}$, Ö. Dereli $^{3}$ and H.S. Kilic ${ }^{1, \text { a }}$ \\ ${ }^{1}$ Department of Physics, Faculty of Science, Selçuk University, Konya, Turkey \\ ${ }^{2}$ Technical Sciences Vocational High School, Selçuk University, Konya, Turkey \\ ${ }^{3}$ Department of Physics, Faculty of A. Keleşoğlu Education, Necmettin Erbakan University, Konya, Turkey
}

\begin{abstract}
Xylenol is a phenolic chemical substance having two methyl groups and one hydroxyl group attached to benzene ring and has six isomers. 2,4-xylenol is only isomer of xylenol molecule that is in liquid phase while remaining isomers are all in a crystal form at room temperature. In the scope of this study, we have experimentally investigated ionization and dissociation nature of xylenol isomers. All experiments were carried out by using Time of Flight Mass Spectrometry (TOF-MS) system coupled with a femtosecond laser system. The laser pulse power dependent multiphoton ionization of xylenol isomers were investigated by using IR $(800 \mathrm{~nm})$ femtosecond laser pulses having a pulse width of $\sim 90 \mathrm{fs}$ in duration and laser intensities changing from $2.6 \times 10^{13}$ to $2.6 \times 10^{14} \mathrm{~W} / \mathrm{cm}^{2}$. Theoretically, molecular orbitals (LUMO+1, LUMO, HOMO, HOMO-1), vertical and adiabatic ionization energies were calculated using Density Functional Theory (DFT) with B3LYP functional and 6-311++G(d,p) basis set by following geometry optimization and performing conformational analysis.
\end{abstract}

Keywords: Lasers (42.55.-f), femtochemistry (82.53.-k), multiphoton ionisation (33.80.Rv), time of flight mass spectrometry (82.80.Rt), Density Functional Theory (31.15.E-)

\footnotetext{
a) Corresponding author. Tel.: +90 33222318 56, fax: -90 3322412499.

E-mail address: hamdisukurkilic@ selcuk.edu.tr; (H.S. Kilic).
} 


\section{INTRODUCTION}

Xylenol (dimethyl phenol) is an organic compound which has six isomers. It has molecular structure $\left(\mathrm{CH}_{3}\right)_{2} \mathrm{C}_{6} \mathrm{H}_{3} \mathrm{OH}$ with 122.166 amu molecular weight and differs from xylene isomer by additional one hydroxyl group attached $(-\mathrm{OH})$. 2,6-Xylenol is the most economically important isomer among all isomers and can be found naturally in coal tar, and however, it is very limited and 2,6-xylenol is mostly produced synthetically. Xylenol isomers dissolve in most organic compounds such as alcohols and acetone [1]. Theoretical calculations and experimental measurements of the ionization potentials of xylenol isomers were given in the literature by using photoelectron spectroscopy (PES) method [2] or theoretically by using a different level of theories (RHF6-31G**) [3]. Atmospheric oxidation and dissociation dynamics were investigated by using Ab-initio methods [4]. HOMO-LUMO energies of the 2,6-Xylenol isomer were calculated by using DFT method [5].

Contamination effects on the soil and impact on the human health of the xylenol isomers were investigated by electron ionization mass spectrometry method [6]. Some groups have investigated these contaminants using Supersonic Jet-Resonance Enhanced Multiphoton Ionization/TOF-MS (SSJ/REMPI/TOF-MS) method and found that 2,4-xylenol is most distinguished isomer among the others [7]. In the other work, the same group has shown that identification of 2,4-xylenol in the sea and river water is possible by using Gas Chromatography/SSJ/REMPI/TOF-MS method [8].

Xylenol and similar volatile organic compounds have side effects on the health and these chemicals are mostly found or produced in the tobacco derivatives and their smokes. Xylenols, as well as propene, butadiene, butene, benzene, pentene, toluene, xylene and cresol chemicals, are detected in the human breath by using single photon ionisation TOF-MS method [9].

There are no theoretical investigations of all isomers of the xylenol in a single work in the literature and also ionization dynamics in the femtosecond timescale of the xylenol isomers were not existed due to the authors' knowledge.

\section{MATERIALS AND METHODS}

In order to determine the most stable molecular conformations, the conformational analysis of the xylenol molecule was performed using semi-empirical method PM3 core type Hamiltonian and the Spartan08 software (Wavefunction Inc., Irvine, CA). Subsequently, geometry optimizations of the all possible conformers were performed by B3LYP functional with 6-311++G(d,p) basis set by using Gaussian03W program [10] to find the most stable conformer structure. After the determination of the most stable conformers of the xylenol isomers, molecular orbitals (LUMO+1, LUMO, HOMO, HOMO-1), vertical/adiabatic ionization energies were calculated using the Density Functional Theory (DFT) with B3LYP functional and 6-311++G(d,p) basis set. In calculation of the adiabatic ionisation energy, geometry of the ionic molecule differs from its neutral (relaxation takes place), geometry optimisation was performed before calculation of frequency. Contrarily in the case of the vertical ionisation, a geometry optimisation was not applied since the ionic molecule has the same geometry with its neutral. A Similar computational scheme was presented in detail elsewhere $[11,12]$.

In this work, a femtosecond (fs) amplifier laser system (Quantronix, Integra-C-3.5, NY, USA) as an energy/ionization source delivering laser pulses with up to $3.5 \mathrm{~mJ}$ energy per pulse at a wavelength of $\sim 800 \mathrm{~nm}$, $\sim 90$ fs pulse duration, $1 \mathrm{kHz}$ repetition rate and $8 \mathrm{~mm}$ output beam diameter was used. The laser beam is tightly focused by a biconvex lens with a $25 \mathrm{~cm}$ effective focal length. During experiments, laser intensities were changed from $2.6 \times 10^{13}$ to $2.6 \times 10^{14} \mathrm{~W} / \mathrm{cm}^{2}$ at the focal point and changed using a circular variable metallic neutral density filter (Newport, CA, USA). Xylenol isomers obtained from Alfa Aeser of a $>98 \%$ purity (2,5xylenol from Sigma Aldrich $>99 \%$ purity) were used without further sample purification. The sample in the sample container was externally heated by a heat gun to obtain sufficient sample pressure in the ionisation chamber and remove residual gases trapped in the crystal from xylenol isomers (except 2,4-xylenol which is in the liquid phase at the room temperature). Before data was taken, samples introduced to the ionisation chamber until the pressure increases upto a few times $10^{-2}$ mbar and samples was degassed and samples were introduced effusively to the ionization region. Mass spectral resolution of the system measured to be $\sim 200$ at the $\mathrm{m} / \mathrm{z}=100$ amu. Data recording and analyses of the mass spectra were performed by using custom built MATLAB program [13]. Details of fs-L-TOF-MS system were described in elsewhere [14].

\section{RESULTS AND DISCUSSION}

The conformational analysis of the xylenol molecule was performed using semi-empirical method PM3 core type Hamiltonian. In order to find conformers we set each carbon and methyl group bond $\left(\mathrm{C}-\mathrm{CH}_{3}\right)$ a 12 fold $(30$ degree per step) rotation and 36 fold (10 degree per step) rotation for each carbon-hydroxy $(\mathrm{C}-\mathrm{OH})$ group bond and searched for 5184 possible conformers and we found; 10, 10, 9, 6, 3 and 11 different conformers for 2,3xylenol, 2,4-xylenol, 2,5-xylenol, 2,6-xylenol, 3,4-xylenol and 3,5-xylenol, respectively. In order to determine 
the most stable conformations of xylenol molecule, the DFT calculations with the B3LYP/6-311++G(d,p) basis set have been used, and most stable conformers of the isomers are shown in Fig. 1. To determine optimized molecular geometry, energy values for each molecule were compared. Energy values (-386.2110247, $386.2127534,-386.2135923,-386.2140374,-386.2125223,-386.2141071)$ and dipole moments $(2.1106,1.7725$, $1.4345,1.483,1.8624,1.4664)$ of the isomers were calculated for; 2,3-xylenol, 2,4-xylenol, 2,5-xylenol, 2,6xylenol, 3,4-xylenol, 3,5-xylenol, respectively. HOMO-LUMO energies and the bandgap values of the xylenol isomers presented in Table 1. Molecular energies, dipole moments and HOMO-LUMO energies for adiabatically/vertically ionised isomers are presented in Table 2 and 3 and it can be seen from literature that they are in consistent with the experimental works given elsewhere [2-5]. In Table 2 we present the adiabatic and vertical ionization energies of the xylenol isomers and energy difference relative to its neutral (relative energy column). Also, we presented the comparison of the calculated molecular properties of the 2,6-xylenol (and full structures for xylenol isomers available in the supporting information) with results presented in the literature [5].

Mass spectra of xylenol (122 amu) isomers are given in Fig. 2 given in relative ion intensities against mass to charge ratio $(\mathrm{m} / \mathrm{z})$ for the $1000 \mathrm{~mW}$ laser pulse power. Dissociation of the 2,3-xylenol (and similarly 2,4xylenol) isomer begin with the appearance of the $\mathrm{H}^{+}$ion peak and with increasing laser power $\mathrm{C}_{1}$ ion peak, $\mathrm{C}_{1} \mathrm{H}_{n}$ group ions and molecular ion peaks were observed. Similar ionisation/dissociation pattern was observed for the 2,5-xylenol with an additional $\mathrm{C}_{2} \mathrm{H}_{\mathrm{n}}$ group and $\mathrm{m} / \mathrm{z}=106$ (-O loss). 2,6-xylenol has followed a similar process in the case of less laser pulse power $(100 \mathrm{~mW})$.

$\mathrm{H}^{+}$ion peak was the first observed peak for 3,4-xylenol and 3,5-xylenol in the case of lowest laser power while parent ion peak intensity becomes a dominant one as laser power increased for these isomers.

Laser pulse power (intensity) dependant ionisation results were revealed that at low-intensity regime ID and DI processes in competition and ID process dominate spectra with increasing laser intensity. In the low laser intensity regime, lower order multiphoton processes can be taken place and the HOMO-LUMO transition is within the limit of the three or four-photon excitation scheme. Calculated HOMO-LUMO energy gap presented in Table I and which are calculated to be between 5.598-5.761 eV. Therefore, relaxation from the excited states can affect the ionization process and investigation of these molecular energy levels can enlighten the relaxation pathways.

In the case of the 2,3-xylenol, 2,4-xylenol and 2,5-xylenol isomers, ion intensities were reached in saturation about $\sim 1000 \mathrm{~mW}$ laser power while similar process was observed at the $\sim 500 \mathrm{~mW}$ lase pulse power values for remaining isomers due to the log-log graph in Fig. 3. Ions with $\mathrm{m} / \mathrm{z}$ ratios of $1\left(\mathrm{H}^{+}\right), 12\left(\mathrm{C}^{+}\right), 15\left(\mathrm{CH}_{3}^{+}\right), 17$ $\left(\mathrm{OH}^{+}\right), 105\left([\mathrm{M}-\mathrm{OH}]^{+}\right), 106\left([\mathrm{M}-\mathrm{O}]^{+}\right), 107\left([\mathrm{M}-\mathrm{CH} 3]^{+}\right), 121\left([\mathrm{M}-\mathrm{H}]^{+}\right)$and $122\left(\mathrm{M}^{+}\right)$were plotted from bottom to top for all isomers.

Slopes of the curves for the ion intensity versus laser pulse power in $\log$-log graph for the molecular ion $[\mathrm{M}]^{+}$ of the xylenol isomers were 3.22, 3.11, 3.77, 3.63, 6.29 and 6.12. In the literature, ionisation potentials were measured $\sim 8-9 \mathrm{eV}$ by using PES (Photoelectron Spectroscopy). Only 3,4-xylenol and 3,5-xylenol isomers have 6-photon ionisation process (which is pure ID process) and consistent with other experimental works and calculated vertical ionization energies presented in Table II.

Slopes of the other ion peaks (ion intensity versus laser pulse power $\log$ - $\log$ graph) have the similar values that was observed for molecular ion. So, it can be concluded that these ions originated from the same precursor (molecular ion).

\section{ACKNOWLEDGMENT}

Authors kindly would like to thank,

- Scientific Research Projects Coordinator office of Selçuk University for financial support via Project Numbers: 161210011 and 16401054.

- $\quad$ Scientific and Technical Research Council of Turkey (TUBITAK) for financial support via Grant No: 1649B031405880.

The data presented in this work will be as a part of Ph.D. thesis of the Abdullah KEPCEOĞLU.

\section{REFERENCES}

[1] H. Fiege, Cresols and Xylenols. (2000).

[2] T. Kobayashi and S. Nagakura, Bulletin of the Chemical Society of Japan 47, 2563 (1974).

[3] D. M. Yu and L. K. F, Applied Physics Research 4 (2012). doi:10.5539/apr.v4n3p152.

[4] L. Sandhiya, P. Kolandaivel, and K. Senthilkumar, J Phys Chem A 117, 4611 (2013). doi:10.1021/jp3120868.

[5] M. Arivazhagan and J. Senthil kumar, Spectrochim Acta A Mol Biomol Spectrosc 137, 490 (2015). doi:10.1016/j.saa.2014.08.054.

[6] S.-Y. Liu and J.-M. Bollag, Water, Air, and Soil Pollution 25, 97 (1985). doi:10.1007/bf00159628. 
[7] H. Tsukatani, H. Okudaira, T. Uchimura, T. Imasaka, and T. Imasaka, Analytical Sciences 25, 599 (2009). doi:10.2116/analsci.25.599.

[8] H. Tsukatani, H. Okudaira, O. Shitamichi, T. Uchimura, and T. Imasaka, Anal Chim Acta 682, 72 (2010). doi:10.1016/j.aca.2010.09.043.

[9] F. Muhlberger, T. Streibel, J. Wieser, A. Ulrich, and R. Zimmermann, Anal Chem 77, 7408 (2005). doi:10.1021/ac051194+.

[10] M. Frisch et al., (2008).

[11] A. Kepceoğlu, H. Kılıç, and Ö. Dereli, AIP Conference Proceedings 1815, 030008 (2017).

[12] D. Sajan, Y. Erdogdu, R. Reshmy, Ö. Dereli, K. K. Thomas, and I. H. Joe, Spectrochimica Acta Part A: Molecular and Biomolecular Spectroscopy 82, 118 (2011).

[13] A. Kepceoğlu and H. Ş. Kılıç, International Journal of Applied Mathematics, Electronics and Computers 4, 57 (2016). doi:10.18100/ijamec.263976.

[14] A. Kepceoğlu, Y. Gündoğdu, K. W. D. Ledingham, and H. S. Kilic, AIP Conference Proceedings 1722 , 060004 (2016). 
Table I. HOMO-LUMO energies and band-gap values of the xylenol isomers

\begin{tabular}{cccc}
\hline Isomers & $\boldsymbol{E}_{L U M O}(\boldsymbol{e V})$ & $\boldsymbol{E}_{\text {HOMO }}(\boldsymbol{e V})$ & $\boldsymbol{E}_{\text {gap }}(\boldsymbol{e V})$ \\
\hline 2,3-xylenol & -0.450 & -6.143 & 5.693 \\
2,4-xylenol & -0.407 & -6.005 & 5.598 \\
2,5-xylenol & -0.404 & -6.128 & 5.724 \\
2,6-xylenol & -0.436 & -6.113 & 5.677 \\
3,4-xylenol & -0.391 & -6.025 & 5.635 \\
3,5-xylenol & -0.410 & -6.171 & 5.761 \\
\hline
\end{tabular}


Table II. Molecular energies and dipole moment values (calculated for adiabatically or vertically ionised isomers at first six and second six row).

\begin{tabular}{c|ccccccc}
\hline \hline Isomers & $\begin{array}{c}\text { Energy } \\
\text { (Hartree) }\end{array}$ & $\begin{array}{c}\text { Relative } \\
\text { Energy } \\
\text { (Hartre) }\end{array}$ & $\begin{array}{c}\text { Relative } \\
\text { Energy } \\
(\mathbf{e V})\end{array}$ & $\begin{array}{c}\text { Relative } \\
\text { Energy } \\
(\mathbf{k J / m o l})\end{array}$ & $\begin{array}{c}\text { Relative } \\
\text { Energy } \\
(\mathbf{k c a l / m o l})\end{array}$ & $\begin{array}{c}\text { Relative } \\
\text { Energy } \\
\left(\mathbf{c m}^{-1}\right)\end{array}$ & $\begin{array}{c}\text { Dipole } \\
\text { Moment } \\
(\mathbf{D})\end{array}$ \\
\hline 2,3-xylenol & $-385,9194324$ & 0,2915923 & 7,938 & 765,57561 & 182,97709 & 63995,76428 & 0,4900 \\
2,4-xylenol & $-385,9278625$ & 0,2848909 & 7,752 & 747,981137 & 178,771907 & 62525,01241 & 0,9681 \\
2,5-xylenol & $-385,9241912$ & 0,2894011 & 7,875 & 759,822667 & 181,602103 & 63514,866 & 1,7426 \\
2,6-xylenol & $-385,9242656$ & 0,2897719 & 7,885 & 760,795992 & 181,834734 & 63596,22792 & 1,3862 \\
3,4-xylenol & $-385,926695$ & 0,2858274 & 7,778 & 750,439707 & 179,35952 & 62730,5285 & 1,0259 \\
3,5-xylenol & $-385,9229901$ & 0,2911171 & 7,922 & 764,327815 & 182,67886 & 63891,45896 & 1,5426 \\
\hline 2,3-xylenol & $-385,9120673$ & 0,29895742 & 8,135 & 784,9127062 & 187,5987706 & 65612,18497 & 0,5653 \\
2,4-xylenol & $-385,8905557$ & 0,3221977 & 8,768 & 845,929983 & 202,18226 & 70712,72263 & 1,3186 \\
2,5-xylenol & $-385,8847902$ & 0,3288021 & 8,947 & 863,269966 & 206,326618 & 72162,20128 & 1,6523 \\
2,6-xylenol & $-385,9166389$ & 0,2973985 & 8,093 & 780,819735 & 186,620526 & 65270,0466 & 1,5021 \\
3,4-xylenol & $-385,8927518$ & 0,3197705 & 8,702 & 839,557448 & 200,659186 & 70180,03164 & 0,9372 \\
3,5-xylenol & $-385,889268$ & 0,3248391 & 8,840 & 852,865162 & 203,839809 & 71292,44606 & 1,7463 \\
\hline \hline
\end{tabular}


Table III. HOMO-LUMO energies and band-gap values of the (values calculated for adiabatically or vertically ionised isomers at first six and second six row) xylenol isomers cations

\begin{tabular}{c|ccc}
\hline \hline Isomers & $\boldsymbol{E}_{\text {LUMO }}(\boldsymbol{e V})$ & $\boldsymbol{E}_{\text {HOMO }}(\mathbf{e V})$ & $\boldsymbol{E}_{\text {gap }}(\boldsymbol{e V})$ \\
\hline 2,3-xylenol & $-5,979$ & $-12,1621$ & 6,182 \\
2,4-xylenol & $-5,913$ & $-12,3695$ & 6,456 \\
2,5-xylenol & $-6,016$ & $-12,1746$ & 6,158 \\
2,6-xylenol & $-5,994$ & $-12,1229$ & 6,129 \\
3,4-xylenol & $-5,916$ & $-12,3602$ & 6,444 \\
3,5-xylenol & $-6,075$ & $-12,1749$ & 6,100 \\
\hline 2,3-xylenol & $-5,890$ & $-12,4117$ & 6,521 \\
2,4-xylenol & $-5,890$ & $-12,2718$ & 6,381 \\
2,5-xylenol & $-5,814$ & $-12,281$ & 6,467 \\
2,6-xylenol & $-5,912$ & $-12,3319$ & 6,420 \\
3,4-xylenol & $-5,804$ & $-12,2612$ & 6,452 \\
3,5-xylenol & $-6,322$ & $-12,2674$ & 5,946 \\
\hline \hline
\end{tabular}




\section{FIGURE CAPTIONS}

Figure 1: (Color online) Most Stable conformers of the xylenol isomers (Grey; Carbon, White; Hydrogen, Red; Oxygen Atoms).

Figure 2: (Color online) Xylenol (122 amu) isomers mass spectra are given as relative ion intensity versus mass to charge ratio $(\mathrm{m} / \mathrm{z})$ for the $800 \mathrm{~nm}$ laser wavelength with $\sim 90 \mathrm{fs}$ pulse width and $1000 \mathrm{~mW}$ laser pulse power. 2,3-xylenol spectrum multiplied by a factor of 5 .

Figure 3: (Color online) Dependence of the relative ion intensity versus laser pulse power for xylene isomers presented in a log-log scale. 
Page 9 of 11

Canadian Journal of Physics

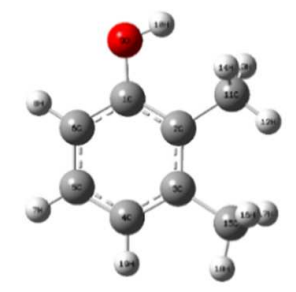

(a) 2,3-xylenol Conformer 1

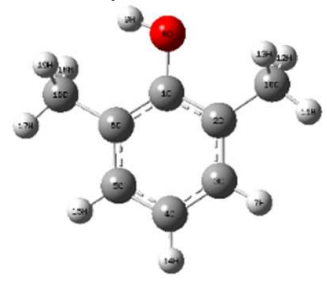

(d) 2,6-xylenol Conformer 1

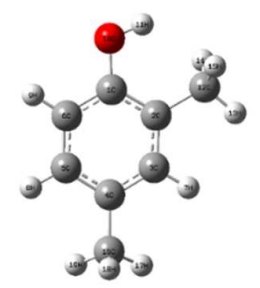

(b) 2,4-xylenol Conformer 1

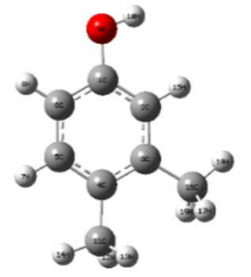

(e) 3,4-xylenol Conformer 1

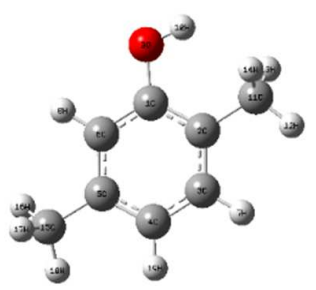

(c) 2,5-xylenol Conformer 1

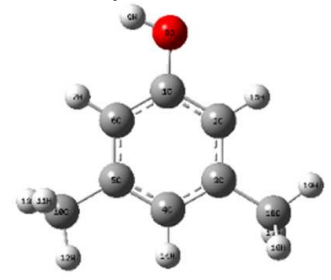

(f) 3,5-xylenol Conformer 1

Figure 1

https://mc06.manuscriptcentral.com/cjp-pubs 


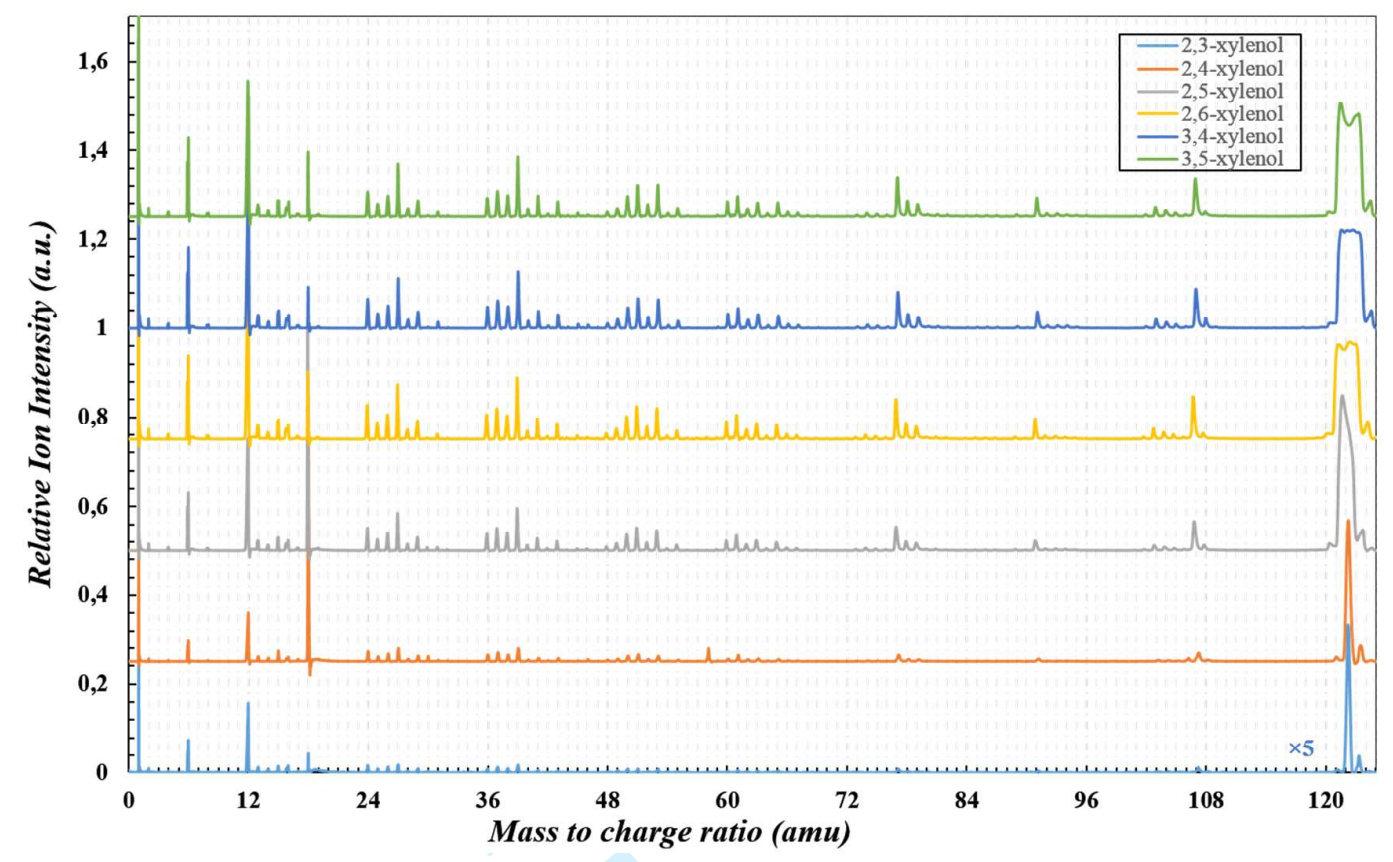

Figure 2 

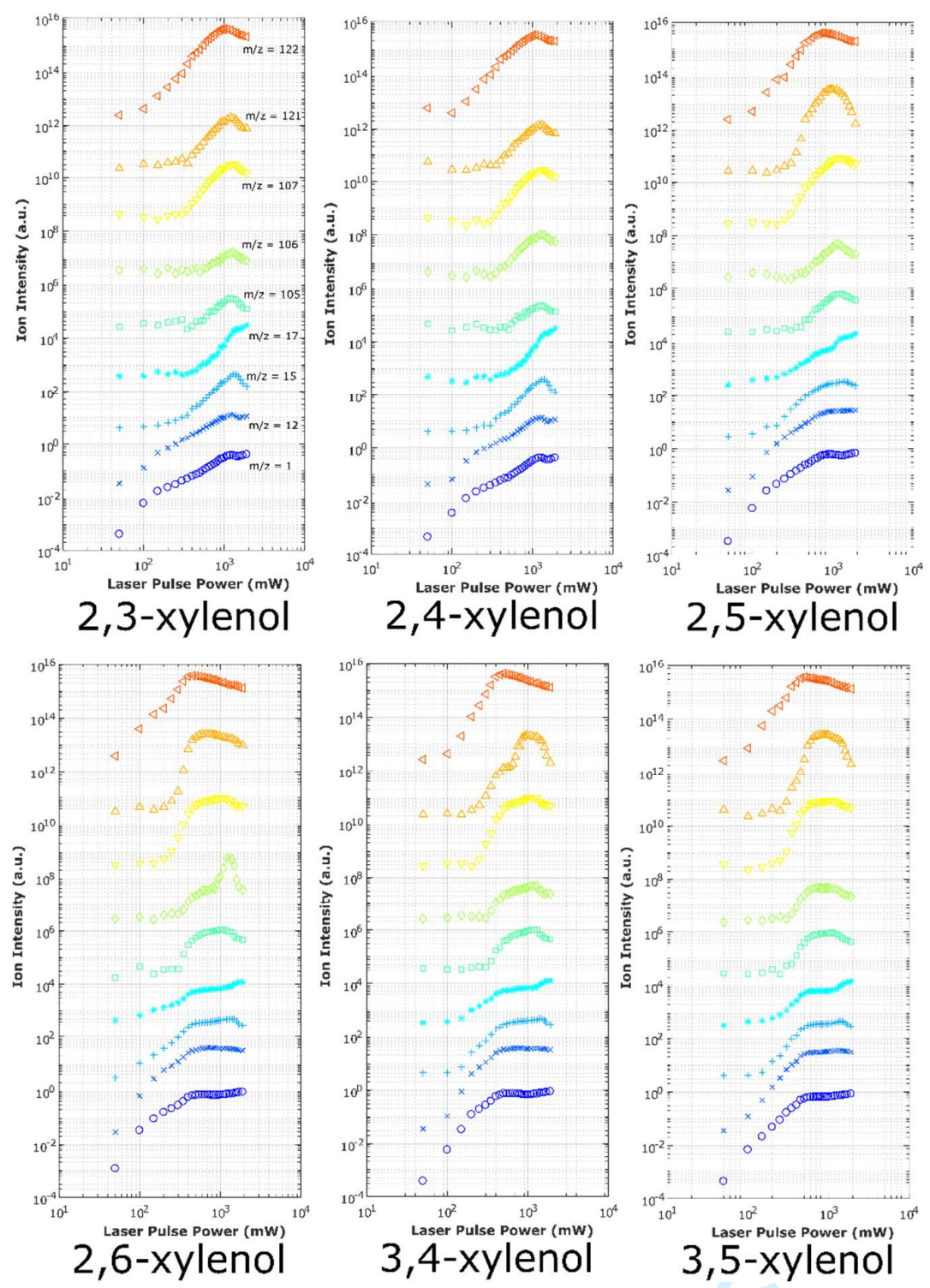

Figure 3 